\title{
Modelling of $E$. coli distribution in coastal areas subjected to combined sewer overflows
}

\author{
Mauro De Marchis, Gabriele Freni and Enrico Napoli
}

\begin{abstract}
$\overline{\text { ABSTRACT }}$
Rivers, lakes and the sea were the natural receivers of raw urban waste and storm waters for a long time but the low sustainability of such practice, the increase of population and a renewed environmental sensibility increased researcher interest in the analysis and mitigation of the impact of urban waters on receiving water bodies (RWB). In Europe, the integrated modelling of drainage systems and RWB has been promoted as a promising approach for implementing the Water Framework Directive. A particular interest is given to the fate of pathogens and especially of Escherichia coli, in all the cases in which an interaction between population and the RWB is foreseen. The present paper aims to propose an integrated water quality model involving the analysis of several sewer systems (SS) discharging their polluting overflows on the coast in a sensitive marine environment. From a modelling point of view, the proposed application integrated one-dimensional drainage system models with a complex three-dimensional model analysing the propagation in space and time of $E$. coli in the coastal marine area. The integrated approach was tested in a real case study (the Acicastello bay in Italy) where data were available both for SS model and for RWB propagation model calibration. The analysis shows a good agreement between the model and monitored data. The integrated model was demonstrated to be a valuable tool for investigating the pollutant propagation and to highlight the most impacted areas.

Key words | coastal water quality, Escherichia coli propagation, integrated urban drainage modelling, receiving water bodies
\end{abstract}

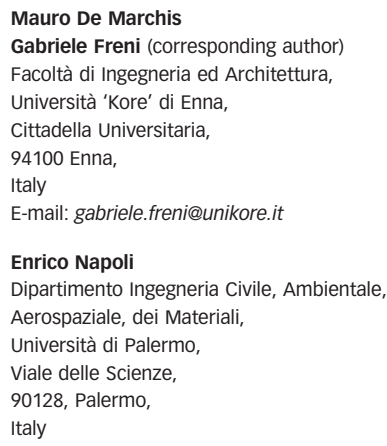

\section{$\overline{\text { INTRODUCTION }}$}

The complex impact of urban pollutants in the marine environment, with reference to coastal regions, requires the use of integrated models able to analyse, at the same time, sewer systems (SS), wastewater treatment plants (WWTP) and receiving water bodies (RWB). Integrated urban drainage modelling is often defined as the linkage between at least two numerical models of the above mentioned physical systems: SS, WWTP and RWB (Harremoës 2002). An increased interest in scientific research about the importance of such a theme can be found in literature (see among other Fu et al. (20I0) and literature therein reported). In Europe, integrated modelling has been promoted as a promising approach for implementing the Water Framework Directive (Martins et al. 2009). Scientific literature has mainly focussed on receiving rivers firstly because their higher sensitivity to pollution and the risk of pollution accumulation due to the repeated spills, and, secondarily, because the analysis of two-dimensional (2D) and three-dimensional (3D) natural river bodies is still complex and time-consuming (Candela et al. 2009; Olawoyin et al. 20I3; Campisano et al. in press). Particular importance is connected with the analysis of the propagation of pathogens because their concentration in coastal waters may affect their recreational destination (Noble \& Fuhrman 200I; Glasoe \& Christy 2004). Total coliforms (TC), faecal coliforms (FC), Escherichia coli and faecal streptococci (FS) or enterococci are used as bacterial indicators for water quality monitoring and health assessment as each group of bacteria is prevalent in the intestines and faeces of warm-blooded mammals, including wildlife, livestock and humans. These indicators are not pathogens; FC, TC and FS are used because they are much easier and less costly to detect and enumerate than the pathogens themselves (Meays et al. 2004). E. coli is recommended as an indicator of faecal contamination in fresh waters (Donnison 
\& Ross I999); this parameter is proposed as there is usually high correlation between its occurrence and that of a pathogen. The European Directive 2006/7/EC (EC 2006) aims to establish more reliable microbiological indicators and a new approach based on an integrated management of water quality. The two faecal indicator parameters retained in the Directive 2006/7/EC are intestinal enterococci (IE) and $E$. coli, providing the best available match between faecal pollution and health impacts in recreational waters. Although monitoring programmes increase the knowledge about the level of microorganisms and other constituents in urban storm water, the collected data are often used without any consideration of the large uncertainties in such environmental measurements, and modelling can play a relevant role to evaluate such uncertainty and for extending the knowledge provided by available data to an area wider than the monitored one (Bertrand-Krajewski et al. I998; McCarthy et al. 2008). Up until now, the main integrated numerical models linked the SS with one-dimensional (1D) or 2D hydrodynamic models (see among others, Schulz et al. (2009) and Vijay et al. (20I0)), thus reducing the precision of the model in the vertical direction by neglecting the vertical mixing. Recently Umgiesser et al. (2008) and later Scroccaro et al. (20IO) pointed out the importance of using a 3D hydrodynamic model to analyse the bacterial dispersion in water bodies, showing that the use of 2D models may hide physical processes in the vertical column. Regarding the degradation of $E$. coli, several levels of refinement can be used to model microbial decay in coastal environments. The two main possibilities are the assumption of a constant decay rate and the inclusion of a time-dependent decay rate. In this latter case, the decay rate can be obtained as a function of different parameters such as sunlight intensity, temperature or salinity. An intermediate approach is the assumption of constant day-and night-time decay rates in order to consider the effect of sunlight radiation on bacterial decline. Examples of the different approaches can be found in works such as GarciaBarcina et al. (2002) and Zhao et al. (2013) for a constant decay rate, Kashefipour et al. (2006) for constant day/night decay rates, or Canteras et al. (I995), Harris et al. (2004) and Kashefipour et al. (2006) for non-constant decay rates.

The objective of the research was the development of an integrated model linking urban drainage models and a detailed 3D RWB model. This is the first application of the proposed integrated model, although the urban drainage and the 3D hydrodynamic models have been favourably used separately in similar environmental applications, see De Marchis et al. (2012) for the 3D RWB model and Freni et al. (20I0a, b) for the urban drainage water quality model. This tool, once calibrated, can be useful to investigate the propagation of pollutants and identify the of most impacted areas of the RWB. The tool can be also used, coupled with uncertainty analysis, to investigate model reliability and to guide monitoring campaigns. The paper is focussed on model description and calibration leaving the possible applications to further studies. The integrated approach was tested in a real case study (the Acicastello bay in Italy) where data were available both for SS model and for RWB propagation model calibration. In that case a monitoring campaign was carried out in summer 2004 involving discharge and pathogens loads monitoring in the urban catchments and wind, currents and polluting concentrations in the marine environment.

\section{THE NUMERICAL MODEL}

The model was obtained by the integration of two parts developed by means of open-source software: the catchment and sewer model developed by means of SWMM (Storm Water Management Model) (Huber \& Dickinson 1988), available at http://www.epa.gov/nrmrl/wswrd/wq/models/ swmm, and the RWB model developed by means of PANORMUS - PArallel Numerical Open-souRce Model for Unsteady flow Simulation (De Marchis \& Napoli 2008), available at http://www.panormus3d.org. The first model was used for simulating the urban areas, the urban combined drainage system and the small ephemeral rivers that receive urban waters and deliver them to the sea. The latter model was used for simulating the hydrodynamics in the coastal area and the diffusion of pollutants depending on the different driving forces. The two modules can be run separately and they are interconnected by outputinput file exchange: the modelling outputs, derived as time series describing water quantity and quality variables, evaluated at the urban water system outfalls and at the ephemeral river mouths, are transferred to the RWB model as input.

\section{Catchment and sewer model}

The EPA SWMM (5.022 version) was used to simulate the urban drainage network and the small natural catchments that are connected to the sewer outfalls; this model allows the user to select different mathematical models to describe the runoff formation and propagation in SS (Huber \& Dickinson ig88). A distributed 'non-linear reservoir' was adopted to simulate the surface runoff, taking into account the surface storage, as an initial hydrological loss, and the 
infiltration phenomena using the Horton equation. Rainfall runoff routing was solved by coupling the continuity equation with the Manning equation, thereby obtaining a non-linear reservoir scheme. The complete 1D De SaintVenant equations were used to simulate the flow propagation into the SS and in the rivers by adopting an iterative explicit mathematical solver. A water quality module was used to simulate the build-up and wash-off of pollutants from the catchment surfaces. The widely applied Alley \& Smith (I98I) model (Equation (1)) was used in the present paper for build-up analysis:

$$
\begin{aligned}
M_{\mathrm{a}}= & \frac{B}{D}[1-\exp (-D \cdot \mathrm{ADWP})] \cdot A \cdot \mathrm{IMP}+M_{r} \\
& \cdot \exp (-D \cdot \mathrm{ADWP})
\end{aligned}
$$

where the symbols assume the following meaning:

- $M_{\mathrm{a}}$ is the mass of solids accumulated on the catchment surface [kg];

- $B$ is the build-up rate of solids due to the different phenomena which influence the accumulation on the catchment impervious area $\left[\mathrm{kg} \mathrm{ha}^{-1} \mathrm{~d}^{-1}\right]$;

- $D$ is a spreading coefficient which represents the dispersion of the particles due to the wind, traffic and biological and biochemical degradation $\left[\mathrm{d}^{-1}\right]$;

- $A$ is the catchment area [ha];

- IMP is the ratio between the impervious area and the total area;

- ADWP is the antecedent dry weather period [h];

- $M_{r}$ is the mass remaining on the catchment at the end of the previous meteorological event [kg].

The original formulation by Jewell \& Adrian (1978) was used for wash-off analysis, in which $M_{\mathrm{e}}(\mathrm{kg})$ is the mass entering the network between $t$ and $t+\Delta t(\mathrm{~h}), M_{\mathrm{a}}$ is the mass on the catchment at time $t, P_{\mathrm{n}}$ is the net rainfall intensity $(\mathrm{mm} / \mathrm{h})$ and $\Delta t$ is the time step:

$M_{\mathrm{e}}=M_{\mathrm{a}} \cdot\left[1-\exp \left(-k_{\mathrm{w}} \cdot \Delta t\right)\right]$

where $k_{\mathrm{w}}=$ Arra $\cdot P_{n}{ }^{\mathrm{Wh}}$, a proportionality coefficient which depends on the physical and dimensional characteristics of the particles and on the rainfall intensity and requires the calibration of two parameters, the wash-off factor, Wh (-), and the wash-off coefficient, Arra $\left(\mathrm{mm}^{-\mathrm{Wh}} \mathrm{h}^{(\mathrm{Wh}-1)}\right)$.

E. coli die-off in the urban water systems was neglected because the runoff travel time in the system is around 60 minutes and the percentage of $E$. coli concentration reduction should be in the range of $1-3 \%$ according to literature values (McCarthy et al. 2008).

\section{RWB model}

The marine environment was modelled by means of the fully 3D numerical model PANORMUS. The PANORMUS is an in-house finite-volume model and is able to solve the Reynolds-averaged momentum and mass balance differential equations on a curvilinear structured grid. The incompressible Reynolds-averaged Navier-Stokes and continuity equations, in the summation convention formulation, read:

$$
\begin{aligned}
& \frac{\partial u_{i}}{\partial t}+\frac{\partial u_{i} u_{j}}{\partial x_{j}}-v \frac{\partial^{2} u_{i}}{\partial x_{j} \partial x_{j}}+\frac{\partial p / \rho}{\partial x_{i}}+\frac{\partial \tau_{i j}}{\partial x_{j}}+g \frac{\rho}{\rho_{a}} \delta_{i 3}+f_{i}=0 \\
& i, j=1, \ldots 3 \\
& \frac{\partial u_{i}}{\partial x_{i}}=0 \quad i=0, \ldots 3
\end{aligned}
$$

where $t$ is the time, $x_{i}$ the $i$-th axis (with the east-west, north-south and vertical directions aligned with the axes $x_{1}, x_{2}$ and $x_{3}$, respectively), $u_{i}$ the $i$-th component of the Reynolds-averaged velocity, $\rho$ the water space dependent density, $\rho_{a}$ the reference density, $p$ the Reynolds averaged pressure, $g$ the gravity acceleration, $v$ the kinematic viscosity, $\delta_{i j}$ the Kronecker delta, $f_{i}$ the $i$-th component of the Coriolis acceleration and $\tau_{i j}$ the Reynolds stresses.

As specified above, the turbulent Reynolds stresses $\tau_{i j}$ are modelled using the $k-\varepsilon$ turbulence model in the 'standard' formulation (Launder \& Spalding I974). Specifically, the isotropic eddy viscosity $v_{t}$ is obtained as $v_{t}=c_{\mu} k^{2} / \varepsilon$, where $c_{\mu}$ is a closure parameter, $k$ is the turbulent kinetic energy (TKE) and $\varepsilon$ the dissipation rate of the TKE (for details see De Marchis \& Napoli (2008)).

In order to simulate coastal processes the free surface movements, mainly given by tidal oscillations of low frequency and relatively high amplitude and by low amplitude oscillations (with higher frequency) typical of the wind seiche motion, are calculated according to the kinematic boundary condition:

$$
\frac{\partial h}{\partial t}+u_{1, s} \frac{\partial\left(h+z_{B}\right)}{\partial x_{1}}+u_{2, s} \frac{\partial\left(h+Z_{B}\right)}{\partial x_{2}}-u_{3, s}=0
$$

where $u_{1, \mathrm{~s}}, u_{2, \mathrm{~s}}$ and $u_{3, \mathrm{~s}}$ are the velocities at the free surface along the $x_{1}, x_{2}$ and $x_{3}$ directions, respectively. 
Since the water mass is bounded on the top by a free surface, the pressure can be calculated according to:

$p=g \rho_{a}\left(h-x_{3}\right)+\rho q$

where $q$ is the dynamic pressure. Introducing Equation (6) in Equation (3) results in:

$$
\begin{aligned}
& \frac{\partial u_{i}}{\partial t}+\frac{\partial u_{i} u_{j}}{\partial x_{j}}-v \frac{\partial^{2} u_{i}}{\partial x_{j} \partial x_{j}}+\frac{\partial q}{\partial x_{i}}+\frac{\partial \tau_{i j}}{\partial x_{j}}+g \frac{\rho-\rho_{a}}{\rho_{a}}+\rho_{a} \frac{\partial \eta}{\partial x_{i}} \\
& \quad+f_{i}=0 \quad i, j=1, \ldots 3
\end{aligned}
$$

In Equations (4), (5) and (7), the time- and space-dependent density field is obtained through the resolution of a state equation starting from the salinity $S$ and temperature $\theta$ fields. In order to obtain the $S$ and $\theta$ fields the conservation equations must be resolved:

$$
\begin{aligned}
& \frac{\partial \theta}{\partial t}+\frac{\partial \theta u_{j}}{\partial x_{j}}-\kappa_{\theta} \frac{\partial^{2} \theta}{\partial x_{j} \partial x_{j}}+\frac{\partial \lambda_{\theta j}}{\partial x_{j}}=0 \\
& \frac{\partial S}{\partial t}+\frac{\partial S u_{j}}{\partial x_{j}}-\kappa_{S} \frac{\partial^{2} S}{\partial x_{j} \partial x_{j}}+\frac{\partial \lambda_{S i}}{\partial x_{j}}=0
\end{aligned}
$$

where $\kappa_{\theta}$ and $\kappa_{\mathrm{s}}$ are the molecular diffusivity of temperature and the molecular salt diffusivity, respectively, and $\lambda_{\theta j}$ and $\lambda_{s j}$ are the salinity and temperature fluxes. The initial values of temperature and salinity were chosen taking into account the period of simulation and the region of analysis. Specifically, values of $24{ }^{\circ} \mathrm{C}$ for temperature and $38.6 \mathrm{PSU}$ (practical salinity unit) for the salinity were initially imposed on the model domain. Salinity changes at the free-surface due to evaporation (increasing the water salinity) and precipitation (which, in contrast, reduces salinity) have been neglected because we are mainly interested in wet weather wash-off; thus evaporation is not relevant for the analysis, and the dilution due to incident rainfall is negligible if compared with the contribution from rivers and drainage systems. Being interested in wet weather, the effect of the solar radiation over the water free surface has been neglected. The system of conservation equations for momentum, mass and thermo marine variables (salinity and temperature) can be resolved only using numerical methods, due to the non-linearity of the partial differential equations. The numerical code (PANORMUS) was extensively validated against laboratory results, analytical solutions and experimental observations in natural water bodies, confirming that the model is able to reproduce the hydrodynamic mixing in environmental and industrial applications (see Napoli et al. 2008; De Marchis et al. 20Io; De Marchis \& Napoli 20I2). Further details on the hydrodynamic model and on a free surface environment application can be found in De Marchis et al. (2012). In order to take into account the pollutant dispersion in the coastal regions, the numerical model resolves, jointly with the system of conservation equations for momentum, the conservation equations for any pollutants present in the water body, which are conveyed and diffused by the currents and by turbulence effects according to:

$\frac{\partial C}{\partial t}+\frac{\partial \mathrm{Cu}_{i}}{\partial x_{i}}-\alpha \frac{\partial^{2} C}{\partial x_{i} \partial x_{i}}+\frac{\partial \wedge_{j}}{\partial x_{j}}-F_{\mathrm{c}}=Q$

where $C$ is the tracer concentration, $u_{i}$ is the $i$-th component of the averaged velocity calculated according to the Reynolds averaged Navier-Stokes equations (Equation (7)), $\alpha$ the molecular diffusivity, $\Lambda_{j}$ the turbulent diffusive flux modelled as $\Lambda_{j}=-\Gamma \partial C / \partial x_{j}$, with $\Gamma$ the turbulent diffusivity obtained as the ratio between the eddy viscosity $v_{t}$ and the turbulent Schmidt number. $F_{\mathrm{c}}$ is the horizontal subgridscale diffusion term and $Q$ represents the source term or sink of the concentration and takes into account the bacteria decay time with a first-order kinetic law (Crane \& Moore Ig86; Evison I988):

$Q_{t}=Q_{0} \cdot \exp \left(-K_{b} \cdot t\right)$

where $Q_{0}$ is the initial number of $E$. coli, $Q_{t}$ the number of $E$. coli remaining at time $t$ (days) and $K_{b}$ is the die-off rate constant. The value of $Q_{0}$ is calculated according to the catchment and sewer model and introduced as input data in the RWB model.

Following Scroccaro et al. (20I0), a cautious decay time (e-folding time) of 1 day was used as the decay parameter. In order to reproduce the distribution of the $E$. coli in the water body, the model presented above was integrated with the catchment and sewer model. Specifically, the flow discharges of the sewer outfalls were included in the RWB model as boundary conditions at the coastline. Furthermore, the values of the $E$. coli concentration obtained with the SS model are imposed in the fluid dynamics models as source term at the coastal boundary. At the coastal boundary, a different value of $E$. coli concentration is specified for each outfall.

The computational modelling of pollution dispersion in coastal areas, using a 3D computation fluid dynamics model, is a key issue in order to preserve the environment 
of the coastal area. In order to take account of a real hydrodynamic circulation in the coastal area, the proper conditions have to be assigned at the boundaries. The forces driving the circulation, both variable tidal levels and wind velocity, have been considered as external forces driving the current. The wind speed produces a wind shear stress over the free surface, partially responsible for the hydrodynamic circulation, which is calculated according to:

$\tau_{s}=\rho_{\text {air }} u^{* 2}$

where $\rho_{\text {air }}$ is the air density and $u^{* 2}$ is the air friction velocity at the free surface. This friction velocity can be related to the wind speed $W_{10}$ at the standard height of $10 \mathrm{~m}$ and to the wind drag coefficient $C_{10}$ through the equation:

$C_{10}=\frac{u^{* 2}}{W_{10}^{2}}$

The wind drag coefficient is calculated by the widely employed Wu's formula (Wu I982):

$C_{10}=\left(0.8+0.065 W_{10}\right) \times 10^{-3}$

The wind speed and direction, imposed in the hydrodynamic numerical simulation of the RWB, were registered by the Italian wavemeter and mareographic network.

\section{DESCRIPTION OF THE CASE STUDY}

The integrated model was applied to a real case study: Acicastello urban area near Catania (Italy). The area is characterized by a relevant coastal urbanization, mainly aimed at tourist activities, that was not supported by the construction of an organized urban drainage and wastewater treatment. At the moment, the urban area is served by six different combined drainage systems collecting both wastewater and storm water, with their outfalls directly in the sea or in small ephemeral rivers near the coast (Figure 1). Due to urbanization, small natural rivers were included in the sewer network, becoming a part of the drainage system and delivering natural runoff water into the sewer pipes. Figure 1 shows the main sewer pipes in each area and the connected natural river reaches. The whole area is about 633 ha and it can be easily divided into two parts: the coastal area that is totally urbanized with few small pervious areas (less than $1 \%$ of the total urban area) and an upstream part that is more pervious with runoff coefficients ranging between 0.3 and 0.5 . The main characteristics of the catchments are reported in Table 1, where some information is shown about the characteristics of the six semi-urbanized catchments. All the natural rivers included in the systems are ephemeral; thus they are characterized by high flows during and soon after rainfall events and they are dry for the most part of the year. Natural catchments are very steep, with average slopes between 20 and 70\%, and characterized by clay soils with emergent volcanic rocks, thus
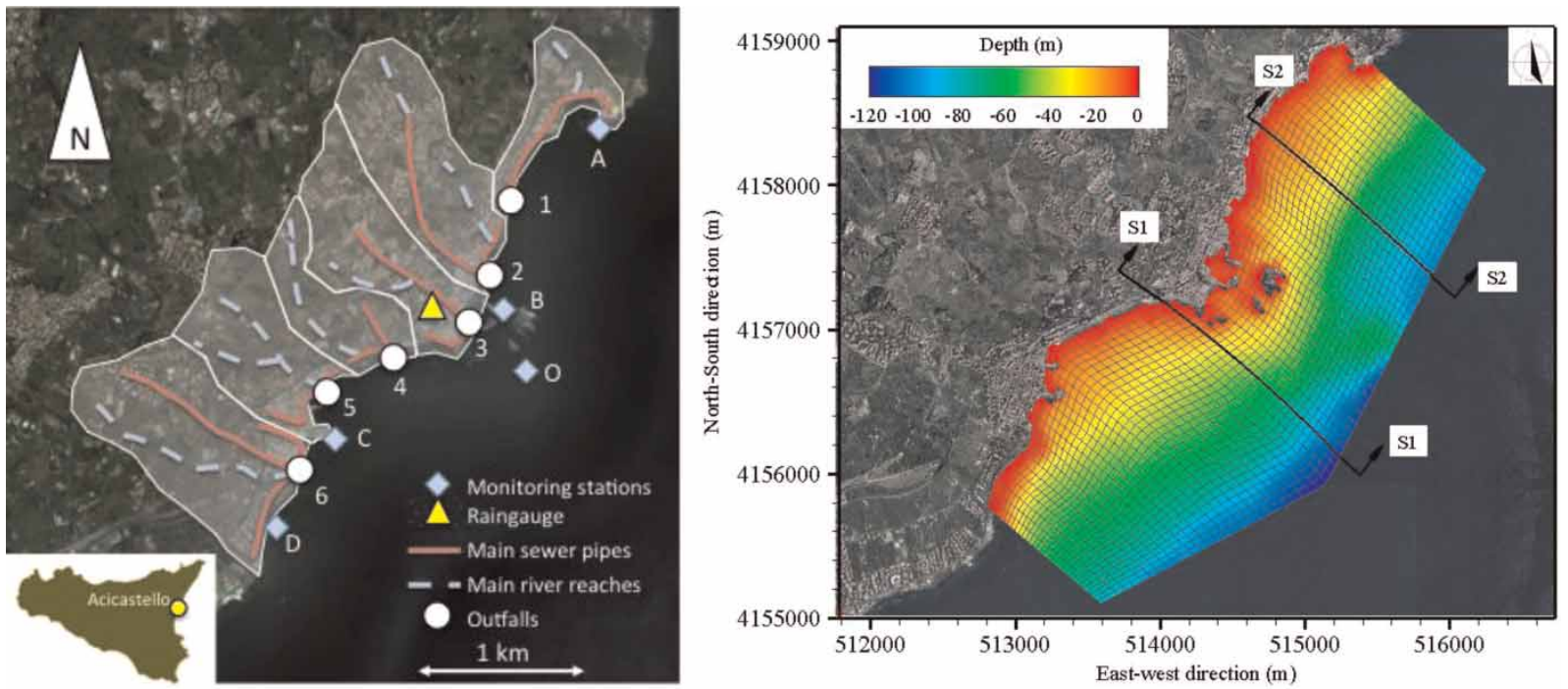

Figure 1 | The main features of the analysed area: the six urbanized catchments (left); the bathymetry of the Acicastello bay (right). 


\begin{tabular}{|c|c|c|c|c|c|c|}
\hline Catchment & $\begin{array}{l}\text { Total area } \\
\text { [ha] }\end{array}$ & $\begin{array}{l}\text { Pervious area } \\
\text { [ha] }\end{array}$ & $\begin{array}{l}\text { Impervious area } \\
\text { [ha] }\end{array}$ & $\begin{array}{l}\text { Population [inhab] - year } \\
2004\end{array}$ & $\begin{array}{l}\text { Natural catchment average } \\
\text { slope [\%] }\end{array}$ & $\begin{array}{l}\text { Urban area average slope } \\
\text { [\%] }\end{array}$ \\
\hline 1 & 58.9 & 24.5 & 34.4 & 6,134 & 34.2 & 12.2 \\
\hline 2 & 125.1 & 95.2 & 29.9 & 5,867 & 38.1 & 23.6 \\
\hline 3 & 108.6 & 81.9 & 26.7 & 4,322 & 24.4 & 7.2 \\
\hline 4 & 65.3 & 23.1 & 42.2 & 6,543 & 19.6 & 3.6 \\
\hline 5 & 97.4 & 60.1 & 37.3 & 5,545 & 45.6 & 21.3 \\
\hline 6 & 180.3 & 136.2 & 44.1 & 7,143 & 65 & 35 \\
\hline
\end{tabular}

increasing the ephemeral characteristics of the rivers. Urban areas are characterized by a combined SS built by concrete circular pipes with diameters between 200 and $800 \mathrm{~mm}$, discharging directly to the sea or in the mouth of the natural rivers that are transformed to rectangular concrete channels in their most downstream reaches. The total served population is equal to 36,500 inhabitants and the average daily water demand is $285 \mathrm{l}$ /(inhab*day). The area was subjected to a large monitoring campaign between March and October 2004 during which both drainage system outfalls (i.e. the mouths of the six ephemeral rivers receiving both untreated sewage waters and rain water) and receiving waters were monitored.

The monitoring campaign had the following characteristics:

- Rainfall was monitored by Riposto rain gauge (Figure 1) with a temporal resolution of 5 minutes; the maximum distance between the raingauge and the catchment boundary is around $2 \mathrm{~km}$ and there are no relevant hills dividing the different catchment, so rainfall data are fully representative of the whole analysed area.

- Sewer flow was monitored by means of ultrasonic probes at the six outfalls with hourly temporal resolution during dry weather periods and with 5 minutes' temporal resolution during rainfall events;

- Urban drainage water quality was monitored by means of 24-bottles automatic samplers connected to the rain gauge and having a sampling time step of 15 minutes; sampling started after $2 \mathrm{~mm}$ rainfall volume was registered in order to collect urban areas' first flush. A dry weather monitoring campaign was also carried out with a sampling time step of $1 \mathrm{~h}$. Monitored water quality included: total suspended solids, biological oxygen demand, chemical oxygen demand, ammonia nitrogen, total Kjeldahl nitrogen, phosphorus, TC and FC.
- Wind and water level were monitored offshore of the analysed coastal area, and the registered data were used as boundary conditions for the RWB hydrodynamic model. Water quality was monitored in four points (named with letters between A and D) by means of manual hourly sampling that was used for verifying the model results (Figure 1).

During the period between March and October 2004, only five events were monitored with sufficient quality (more than $80 \%$ of samples for each monitoring station with sufficient water to perform the analyses for all the analytes) to be usable for model calibration (Table 2).

\section{MODEL CALIBRATION AND ANALYSIS OF RESULTS}

The water quantity module, for each sub-catchment, was fully characterized by seven calibrated parameters (Table 3). The water quality module was defined by four parameters for each sub-catchment (second part of Table 3). Model parameters were initially subjected to sensitivity analysis, where the ranges of the parameters were determined using the literature (Huber \& Dickinson 1988). The model proved to be insensitive to infiltration parameters and such parameters were set to the average value in the

\begin{tabular}{lllll}
\multicolumn{5}{l}{ Table 2 | Main characteristics of the monitored events } \\
Events & $\begin{array}{l}\text { Rainfall } \\
\text { volume }[\mathbf{m m}]\end{array}$ & $\begin{array}{l}\text { Max intensity } \\
\text { [mm/h] }\end{array}$ & $\begin{array}{l}\text { Duration } \\
\text { [min] }\end{array}$ & $\begin{array}{l}\text { Average } \\
\text { intensity [mm/h] }\end{array}$ \\
\hline $25 / 04 / 2004$ & 29.6 & 16.6 & 386 & 3.6 \\
$12 / 05 / 2004$ & 26.2 & 56.8 & 73 & 21.5 \\
$04 / 07 / 2004$ & 22.8 & 11.5 & 214 & 6.4 \\
$12 / 07 / 2004$ & 19.5 & 20.1 & 156 & 7.5 \\
$17 / 07 / 2004$ & 41.4 & 38.2 & 88 & 28.2 \\
\hline
\end{tabular}


Table 3 | SWMM parameters subjected to calibration (against sewer outflow and E. coli concentration): parameters in italics have been fixed to average values because of not being influential

\begin{tabular}{|c|c|c|c|c|c|c|c|}
\hline \multirow[b]{2}{*}{ Parameter } & \multirow[b]{2}{*}{ Sensitivity variation range } & \multicolumn{6}{|c|}{ Urban areas - calibrated values } \\
\hline & & 1 & 2 & 3 & 4 & 5 & 6 \\
\hline Imp. area roughness (Manning) & $0.01-0.03$ & 0.020 & 0.022 & 0.018 & 0.013 & 0.021 & 0.025 \\
\hline Perv. area roughness (Manning) & $0.02-0.1$ & 0.033 & 0.035 & 0.039 & 0.038 & 0.042 & 0.038 \\
\hline Imp. area surface storage $[\mathrm{mm}]$ & $0.1-2$ & 0.3 & 0.8 & 0.4 & 0.6 & 1.1 & 0.9 \\
\hline Perv. area surface storage $[\mathrm{mm}]$ & $0.5-4$ & 2.5 & 2.1 & 3.3 & 3.7 & 2.3 & 2.1 \\
\hline Initial infiltration $\left[\mathrm{mm} \mathrm{h}^{-1}\right]$ & $40-100$ & 70 & 70 & 70 & 70 & 70 & 70 \\
\hline Saturated soil infiltration $\left[\mathrm{mm} \mathrm{h}^{-1}\right]$ & $8-25$ & 15 & 15 & 15 & 15 & 15 & 15 \\
\hline Depletion constant $\left[\mathrm{d}^{-1}\right]$ & $0.001-0.05$ & 0.02 & 0.02 & 0.02 & 0.02 & 0.02 & 0.02 \\
\hline Sewer pipe roughness (Manning) & $0.01-0.03$ & 0.48 & 0.018 & 0.41 & 0.015 & 0.41 & 0.015 \\
\hline Unit accumulation rate $[\mathrm{kg} /(\mathrm{ha} * \mathrm{~d})]$ & $0.5-12$ & 5.5 & 6.7 & 9.2 & 8.5 & 7.3 & 8.5 \\
\hline Dispersion parameter $\left[\mathrm{d}^{-1}\right]$ & $0.05-0.8$ & 0.31 & 0.18 & 0.47 & 0.21 & 0.32 & 0.25 \\
\hline Wash-off coefficient $\left[\mathrm{mm}^{-1}\right]$ & $0.01-2$ & 0.47 & 0.55 & 0.42 & 0.67 & 0.71 & 0.85 \\
\hline Wash-off factor [-] & $0.5-2.5$ & 0.93 & 1.05 & 0.24 & 1.12 & 1.08 & 1.12 \\
\hline
\end{tabular}

Imp.: impervious; Perv.: pervious.

variation range and they were not calibrated. The sensitive parameters were calibrated using the available dataset and maximizing the Nash-Sutcliffe (N-S) criterion (Nash \& Sutcliffe I970). The water quantity modules were calibrated first and then fixed as the water quality modules were calibrated (Table 3). No validation steps were performed due to the small available dataset.

Calibration of the SWMM, for all the analysed events and for all six outfalls, provided good results with N-S efficiencies ranging between 0.65 and 0.73 for outfall discharges and ranging between 0.57 and 0.68 for $E$. coli concentrations. Calibrated flows and concentrations were transferred as input to the RWB model. Table 4 shows N$S$ values for all the seven outfalls for both discharge and E. coli concentration. Figure 2 shows the calibration result for outfall 1, taken as an example. Similar pattern E. coli concentrations were found for the other outfalls; thus these are omitted here. Despite this, it is worthwhile to show the high level of concentration achieved, especially considering the fact that the European Community directive

Table 4 | Values of $\mathrm{N}-\mathrm{S}$ efficiency index for the different monitored events at the outfall of urban rivers

\begin{tabular}{|c|c|c|c|c|c|c|c|c|}
\hline \multirow[b]{2}{*}{ Events } & \multicolumn{8}{|c|}{$\mathrm{N}$-S efficiency index for discharge estimation in each outfall } \\
\hline & 1 & 2 & 3 & 4 & 5 & 6 & 7 & 8 \\
\hline $25 / 04 / 2004$ & 0.69 & 0.68 & 0.65 & 0.72 & 0.66 & 0.71 & 0.71 & 0.68 \\
\hline $12 / 05 / 2004$ & 0.71 & 0.72 & 0.69 & 0.68 & 0.70 & 0.72 & 0.68 & 0.70 \\
\hline $04 / 07 / 2004$ & 0.73 & 0.70 & 0.73 & 0.69 & 0.71 & 0.71 & 0.69 & 0.67 \\
\hline $12 / 07 / 2004$ & 0.72 & 0.72 & 0.68 & 0.72 & 0.69 & 0.70 & 0.72 & 0.66 \\
\hline \multirow[t]{2}{*}{$17 / 07 / 2004$} & 0.65 & 0.68 & 0.66 & 0.69 & 0.70 & 0.69 & 0.68 & 0.68 \\
\hline & \multicolumn{8}{|c|}{$\mathrm{N}$-S efficiency index for $E$. coli concentration estimation in each outfall } \\
\hline Events & 1 & 2 & 3 & 4 & 5 & 6 & 7 & 8 \\
\hline $25 / 04 / 2004$ & 0.57 & 0.65 & 0.58 & 0.64 & 0.57 & 0.68 & 0.67 & 0.64 \\
\hline $12 / 05 / 2004$ & 0.64 & 0.66 & 0.57 & 0.59 & 0.63 & 0.65 & 0.64 & 0.63 \\
\hline $04 / 07 / 2004$ & 0.66 & 0.64 & 0.66 & 0.65 & 0.64 & 0.65 & 0.59 & 0.62 \\
\hline $12 / 07 / 2004$ & 0.68 & 0.63 & 0.58 & 0.68 & 0.62 & 0.68 & 0.57 & 0.59 \\
\hline $17 / 07 / 2004$ & 0.59 & 0.57 & 0.59 & 0.58 & 0.64 & 0.66 & 0.65 & 0.58 \\
\hline
\end{tabular}


(a)

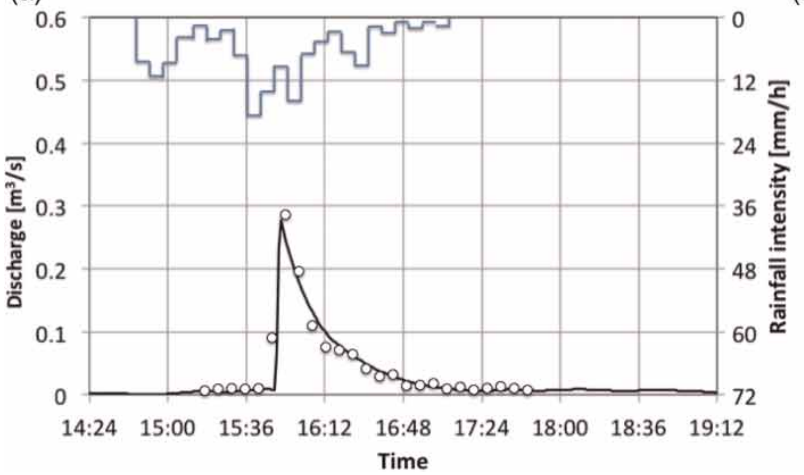

(b)

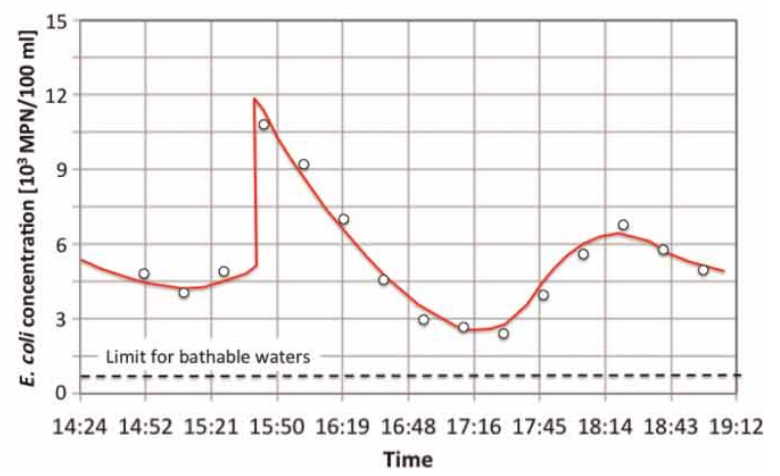

Figure 2 | Discharge at the river mouth (based on main axis) and rainfall intensities (based on the secondary axis). (a) Discharge and (b) E. coli concentration for the event of 12/07/2004 and for outfall 1.

(2006/7/CE) limit of E. coli for bathing water is imposed to the value of $500 \mathrm{MPN} / 100 \mathrm{ml}$ (MPN: most probable number). In light of this, the preliminary analysis of the E. coli dispersion in the water body should be a key issue.

In order to analyse the dispersion of the E. coli in the coastal area, numerical simulations were carried out reproducing the marine environment with a computational domain discretized using $64 \times 128 \times 16$ hexahedral cells in the east-west, north-south and vertical directions, respectively. Due to the domain length, reported in Figure 1, and considering that grid points were uniformly distributed, in the east-west direction the averaged cell size is about $20 \mathrm{~m}$, while in the north-south direction it is about $40 \mathrm{~m}$. In the vertical direction, a non-uniform grid was used with a refinement near the bottom and near the free surface. Specifically, the level of refinement was set according to the hyperbolic function given by:

$d_{k}=0.5 h \cdot[\tanh (\alpha(r-1))+(\tanh (-\alpha)+1)(r-1)+1]$

where $d_{k}$ is the distance of the $k$-th node from the bottom, $r=2(k-1) / n$ is a tuning parameter, with $n$ the number of grid cells in the vertical direction, and $h$ is the water depth. The parameter $\alpha$ controlling the node clustering is locally tuned to obtain a vertical resolution. In the present analysis, the parameter $\alpha$ was tuned to obtain a vertical resolution not higher than $0.5 \mathrm{~m}$ in the top cell. The maximum cell size in the vertical direction is located at middle depth in the region located away from the coast line. The average maximum cell size in the vertical direction is about $20 \mathrm{~m}$. To ensure an appropriate grid resolution, a numerical simulation was performed discretizing the physical domain into $128 \times 256 \times 32$ cells.
Because no discernible differences were found when the grid was refined, the coarse grid was used, thus reducing the computational time cost.

In the vertical direction a non-uniform grid has been used, with a refinement close to the bottom and the free surface. Due to the geometrical complexity of the coastal areas and the presence of small islands, a curvilinear boundary-fitted computational grid was used (Figure 1).

In Figure 1, the marine environment of Acicastello bay is shown. It is characterized by a rocky steep bottom with water depths higher than $80 \mathrm{~m}$ at only $150 \mathrm{~m}$ from the shore. The specific geometric configuration of the coastal region can induce a principal circulation in the vertical planes, characterized by upwelling and downwelling processes close to the coastline and in the open sea, respectively.

The free surface elevation, corresponding to the open boundaries, is updated according to the variation of the registered tidal current, reported in Figure 3. In the figure the wind velocity components imposed over the free surface are plotted too. Both wind velocities and water levels were registered by the Italian mareographic network (IMN). Specifically, the two monitoring stations are located about $5 \mathrm{~km}$ southern of the modelled region. The wind station is located near the coastline, while the water level elevation is measured at the open sea. For details on the position of the stations see the official IMN portal (www.idromare.it), where it is possible to download the used data. Due to the fact that the measurement point is relatively near the region of interest, in this analysis the phase shift of the water level between the station and the model domain is neglected. In the present analysis, a variable in time but constant in space wind was considered, thus neglecting the wind 

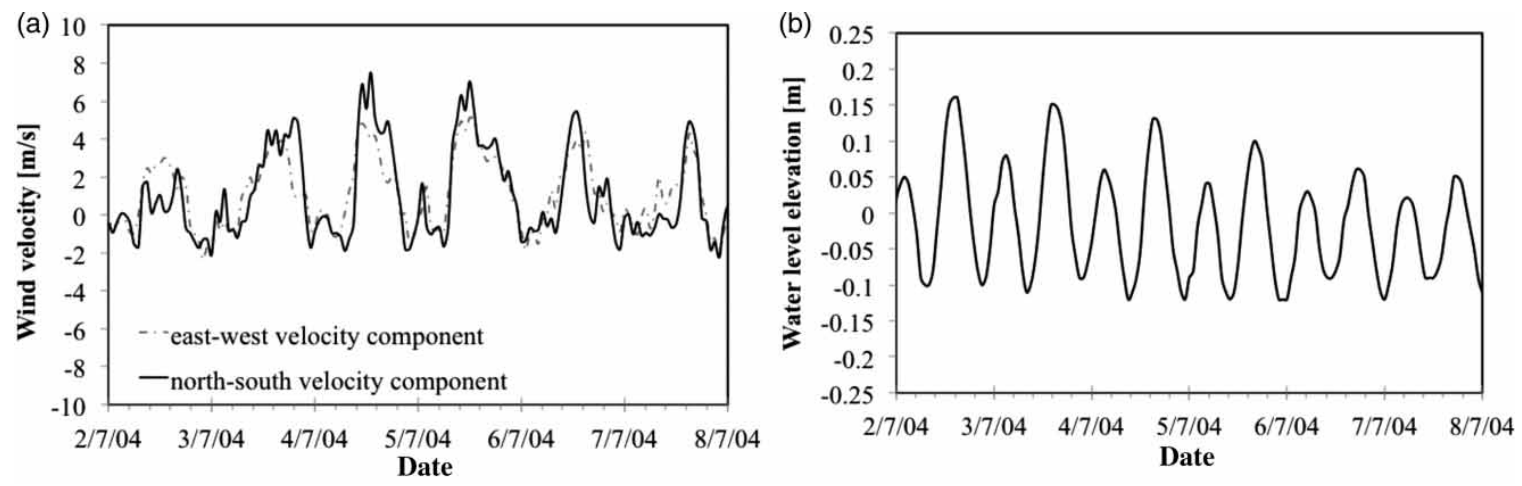

Figure 3 | Forces acting on the water body. (a) Wind velocity components imposed over the free surface (data by the IMN). (b) Free surface elevation in time imposed at the open boundary (data by the IMN). Data available at www.idromare.it.

speed changes occurring close to the coastlines due to the different land and water roughness and temperature. The difference between the land and water roughness causes the development of the internal boundary layer (IBL), changing consequently the wind velocity distribution over the free surface. A variable distribution of the wind over the free surface can produce local variation of the hydrodynamic current. For this reason we are now carrying out further simulation taking into account the IBL in the lowermost part of the atmospheric boundary layer.

Following the recent findings of Roman et al. (2010), when a further current from the open sea is required, on open boundaries an Orlanski condition will be used. Usually this condition is used adding a buffer layer between the effective grid and the open boundary. Here additional currents are neglected. The logarithmic wall-law, with a von Karman constant equal to 0.41 , has been used on the solid boundaries (land and island contours and sea bottom). The same boundary conditions were applied for the momentum, salinity and temperature transport equations. The numerical simulation was carried out from 1st to 15th July, while the results presented here correspond to the period of the field measurement campaign of the E. coli concentration (3rd and 5th July 2004). The first 2 days can be considered a reasonable spin-up period.

E. coli concentrations in the monitoring stations A, B, $\mathrm{C}, \mathrm{D}$ and $\mathrm{O}$ were used to verify the reliability of the model. Figure 4 shows the agreement between modelled and monitored E. coli concentrations in points $\mathrm{O}$, located $385 \mathrm{~m}$ from the coast with $30 \mathrm{~m}$ water depth, D, located $40 \mathrm{~m}$ from the shore with $3.2 \mathrm{~m}$ water depth, and $\mathrm{B}$ located near the mouth of the harbour about $180 \mathrm{~m}$ from the outfall and characterized by a depth of $9 \mathrm{~m}$.
The rainfall events between 2nd and 5th July 2004 are shown. In the points $\mathrm{A}$ and $\mathrm{C}$, not reported here, a concentration profile similar to that observed in the point $\mathrm{D}$ was achieved and thus omitted. The measured values of the $E$. coli used to compare the numerical results were sampled in a monitoring campaign carried out by the Regional Environmental Protection Agency (ARPA).

Both numerical and measured data plotted in Figure 4 were sampled corresponding to the free surface, more specifically $10 \mathrm{~cm}$ below it. The figure shows a good agreement between data and simulations even if the model tends to underestimate peak wet weather concentrations. The figure also shows that there is not a strict correlation between rainfall intensity and $E$. coli concentrations, because of the combination of the sewage water dilution and the different hydrodynamic conditions of the RWB. The system is in fact influenced by the combination of urban runoff and natural catchment runoff. The first is mainly responsible for the E. coli discharge while the second is not characterized by high E. coli concentrations, being originated by non-urbanized natural areas. In contrast, natural catchments produce the most part of the runoff volume. During intense rainfalls, urban pollutant loads are diluted by natural flows, and highest $E$. coli concentrations were monitored during short and small rainfall events in which natural catchments are not saturated and do not provide large contributions to runoff.

Figures 4(a) and 4(b) clearly show that the concentration of $E$. coli is higher than the limit for bathing water only in point $\mathrm{B}$, located near the mouth of the harbour, and about $10 \mathrm{~h}$ after the rainfall event. Furthermore the limit is exceeded for almost $7 \mathrm{~h}$ after the second rainfall event and for $12 \mathrm{~h}$ after the more intense third rainfall 
(a)

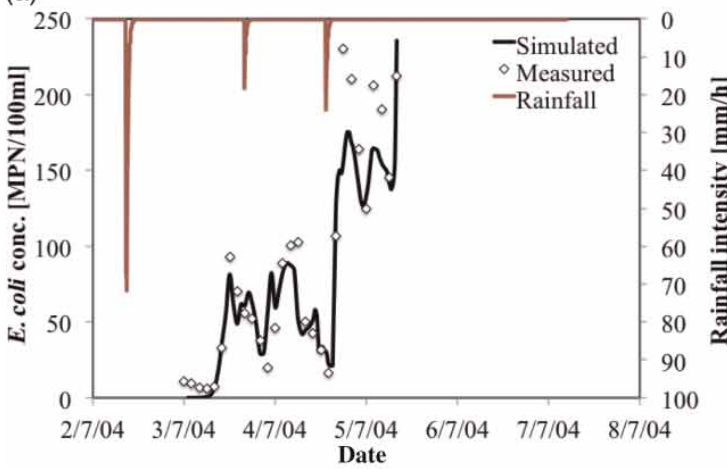

(b)

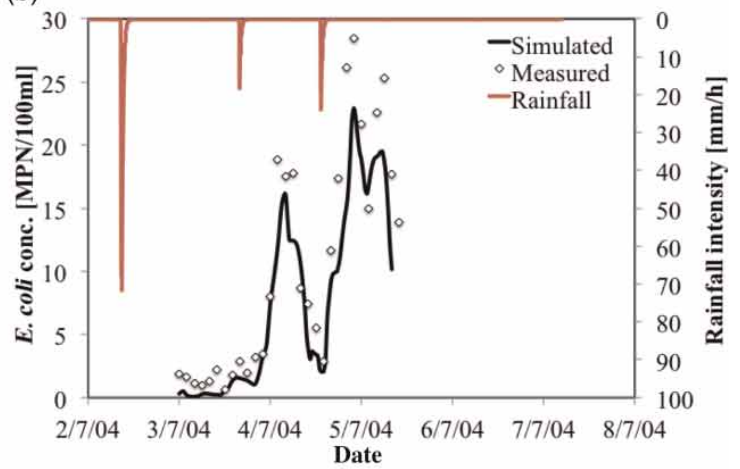

(c)

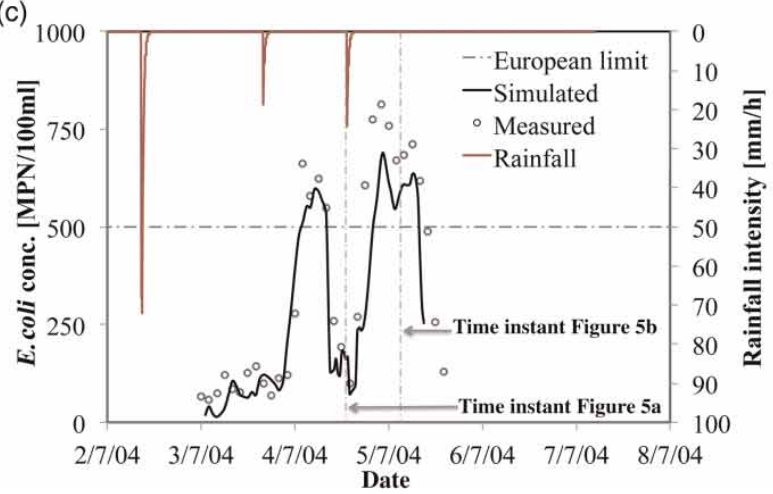

Figure 4 | Comparison between monitored and simulated E. coli concentrations in monitoring stations: (a) O, (b) D and (c) B. For clarity, in point B the horizontal dot-dash line is representative of the European limit, while the two vertical dot-dash lines indicate the instant time chosen for the contour plot of $E$. coli reported in Figure 5 .

event. This confirms a direct correlation between the rainfall events and the E. coli dispersion.

Once the hydrodynamic model had been validated, it was used to estimate $E$. coli concentration fields. Figure 5 shows the contour plot of the $E$. coli concentration at the free surface corresponding to the rainfall event of the 04/07/2004 (Figure 5(a)) and $13 \mathrm{~h}$ after the end of the rainfall event (Figure 5(b)). Figure 5 clearly shows how the effect of the rainfall is a reduction of the concentration. The two plots emphasize the heavy state of contamination of the marine environment especially close to shoreline. For this purpose, in Figure 5 an iso-line is shown of concentration delineating the region where concentration values are higher than the value of $500 \mathrm{MPN} / 100 \mathrm{ml}$ imposed by the European Community directive $(2006 / 7 / \mathrm{CE})$. In this way it is possible to show how the region close to the coastline and to the outfalls exceeds the limit value for bathing water. Specifically, the region between the coast and $300 \mathrm{~m}$ offshore, where the bathing water limit applies, is characterized by the highest values of $E$. coli concentration. In the present case $50 \%$ of the coastline is affected by a concentration of $E$. coli higher than the imposed limit (Figure 5(a)), and also during the third rainfall event (shown in Figure 4). This percentage increases to about 70\% $13 \mathrm{~h}$ later, when the peak of concentration is achieved. Furthermore, Figure 5(b) clearly shows that the region where the concentration of $E$. coli exceeds the European limit is considerably increased beyond the limit of $300 \mathrm{~m}$. Despite this, in some monitoring stations located far away from the outfall, the values of concentration are beneath the limit value (see Figure 4), thus suggesting that the heavy state of contamination is localized in the water region located close to the outfalls. In order to better analyse the importance of using a fully 3D numerical model to reproduce the pollutant dispersion in RWB, showing the mixing of the water column, the $E$. coli concentration along vertical planes is plotted in two different time steps (Figure 6). To emphasize the current direction, in Figure 6 some streamlines are superimposed to the contour of the $E$. coli concentration.

Figure 6(b)-(d) shows that when the current is directed from the free surface toward the bottom layers (see the streamlines direction), a dispersion of the pollutants is achieved, thus increasing the risk of polluting the benthic 


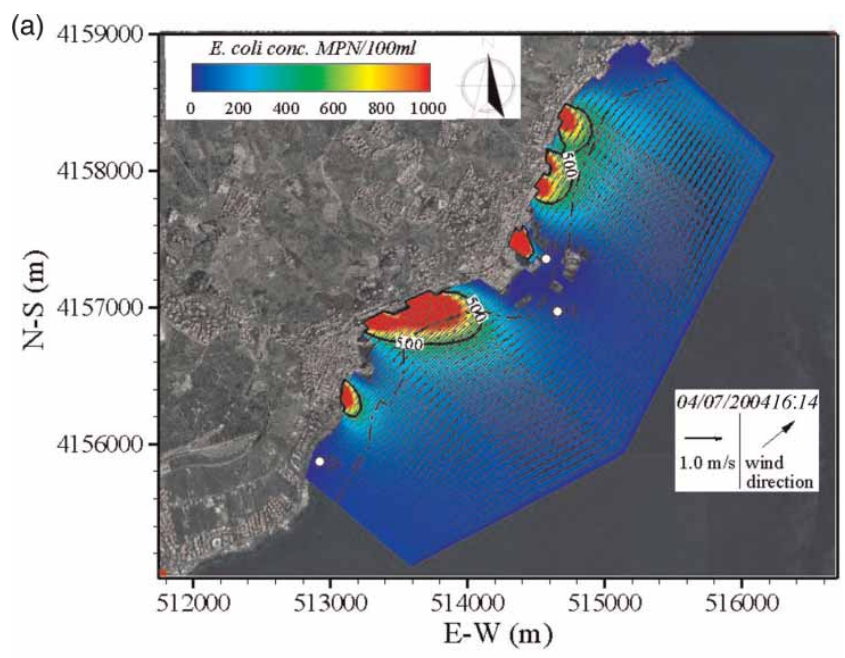

(b)

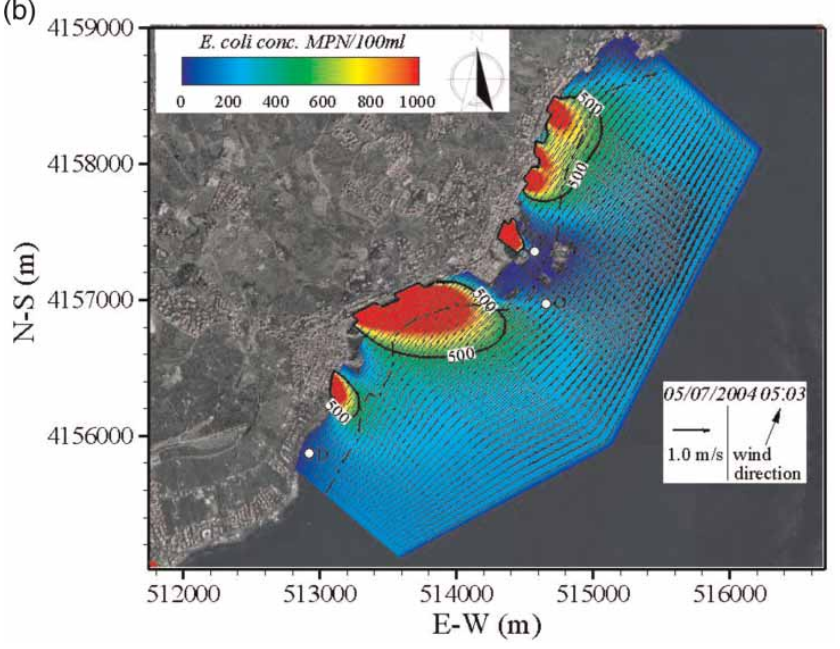

Figure 5 | E. coli concentrations in two different periods: (a) during the rainfall event of 04/07/2004; (b) $13 \mathrm{~h}$ after the rainfall event. Bold line: European limit for bathing water, $500 \mathrm{MPN} / 100 \mathrm{ml}$. Dot-dash line: $300 \mathrm{~m}$ offshore line where bathing water limits apply.

resources. On the other hand, when the current drives the circulation in the opposite direction, toward the free surface, the $E$. coli concentration, below the free surface, is evidently reduced and the pollutants are mainly concentrated in the upper layers.

Figure 6(c) shows that when the wind blows toward the land a large recirculation region near the coastline occurs, causing the dispersion of the $E$. coli concentration from the upper layer to the bottom, while when the wind blows toward the open sea the maximum value of the concentration is achieved in the free surface region away from the coast (see Figure 6(d)). This behaviour can be explained by the typical phenomenon of down welling and up welling.

\section{CONCLUSIONS}

The paper presented the application of an integrated water quality model based on open-source models. The integrated model has the particular feature of integrating a 1D urban drainage model with a 3D hydrodynamic dispersion model for simulating a coastal area. Thanks to the integration of urban drainage models and 3D RWB hydrodynamic models, the information about E. coli sources in urban areas have been linked to hydrodynamic circulation analysis in a simulation tool able to highlight the fate of contaminants in coastal areas. The tool can be used for the analysis of the present environmental state of RWB or for the identification of the best mitigation measures for the reduction of urban pollution impact.

From the analysis of the specific case study, some considerations may be drawn. Despite the coliform mortality rate having been taken into account, the fully 3D hydrodynamic simulations clearly show that, in an open water body, the meteorologic-marine conditions play a fundamental role in the dispersion of the E. coli. The outfall concentration of the order of $10^{4} \mathrm{MPN} / 100 \mathrm{ml}$ (Figure 4(b)) rapidly decreases with the hydrodynamic effect. Despite this, in the bathing region, up to $300 \mathrm{~m}$ from the shoreline, the E. coli concentration exceeds the European limit in about $50 \%$ of the shore length. This percentage could increase to $70 \%$ when rainfall events are repeated and several concentration peaks are considered from the river mouths (Figure 5). Anyway, the extreme peaks of E. coli concentration are mainly confined in the upper layers, with a rapid decrease along the vertical direction. Specifically the $E$. coli concentration decreases by one order of magnitude $1.5 \mathrm{~m}$ below the free surface. The numerical results of the RWB model give a more realistic condition of the contamination state of the bay. In fact, despite the E. coli concentration being slightly reduced along the coast during the rainfall event, the hydrodynamic circulation maintains E. coli contamination on the surface due to the floating of polluted river water over the salty seawater. Up until now, mainly 1D or 2D integrated numerical models have been developed, thus reducing the precision of the model especially in the vertical direction. The 3D model, considered here, represents a preliminary step to improve the preservation of the environment of the sea water in very complex conditions.

Further analysis will be addressed in the future focussing on the propagation of uncertainty from modelling input to the final RWB concentration distributions (see 
(a)
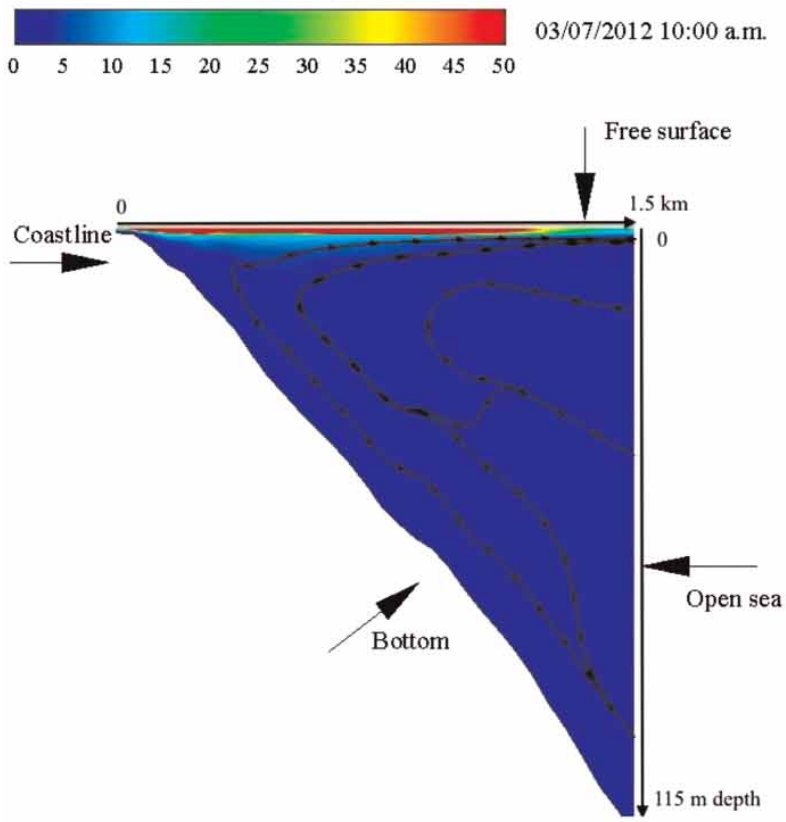

(c)
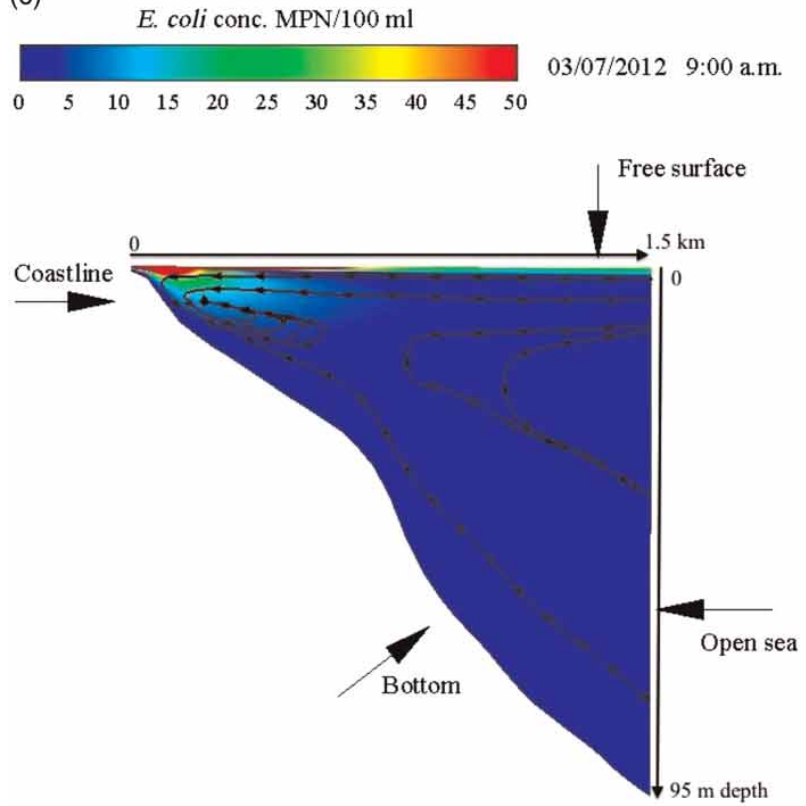

(b)
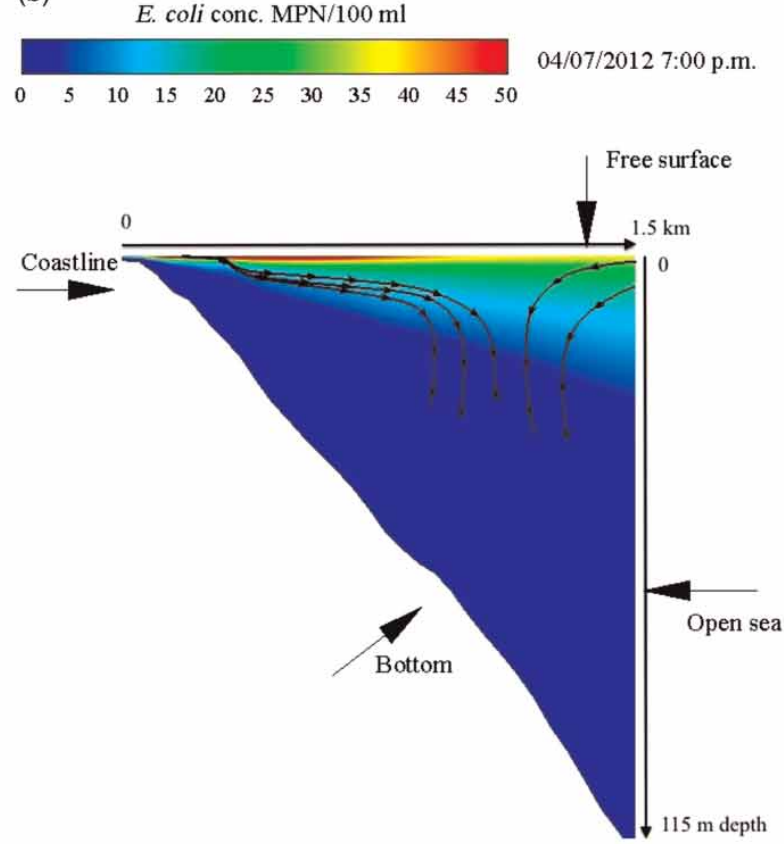

(d)
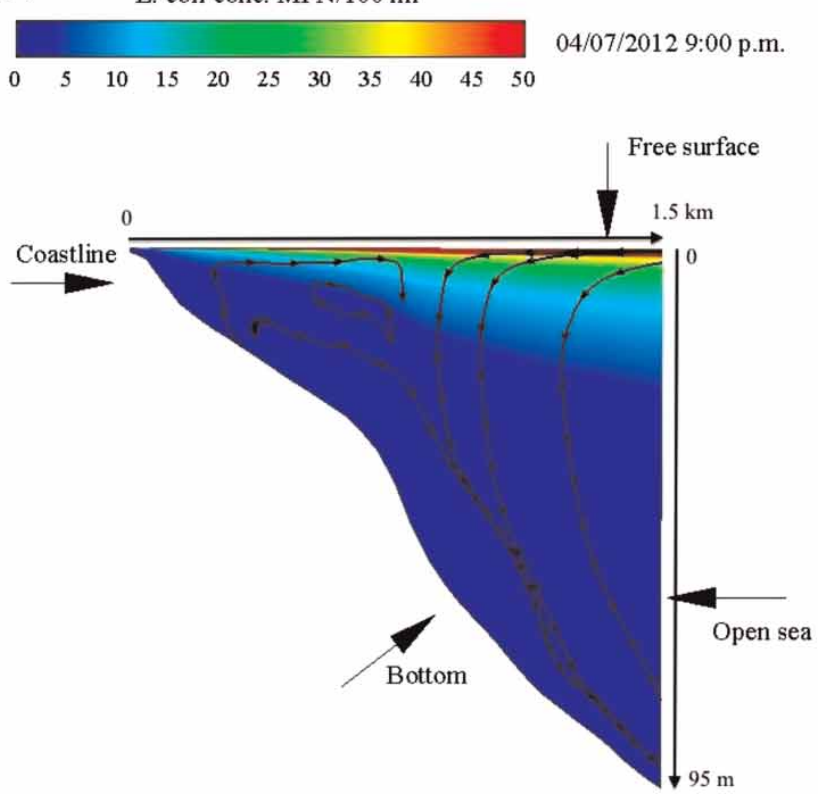

Figure 6 | E. coli concentrations in a vertical plane in two different periods. The sections here considered are S1-S1 ((a), (b)) and S2-S2 ((c), (d)) indicated in Figure 1. Some streamlines (in black) are superimposed to the contour plot of the E. coli. To improve the clarity the vertical scale is distorted by a factor of 15 .

Deletic et al. (2012), Dotto et al. (2012) and the literature cited therein). The ongoing analysis will be focussed on the specific contribution of the temperature and the water salinity on the dilution effect as well as the relative contribution of the hydrodynamic mixing and bacterial decay.

\section{ACKNOWLEDGEMENTS}

The authors would like to acknowledge Italian National Project PON 01_1844 - SIBSAC for providing financial support to the research. 


\section{REFERENCES}

Alley, W. M. \& Smith, P. E. I98I Estimation of accumulation parameters for urban runoff quality modelling. Water Resour. Res. 17 (6), 1657-1664.

Bertrand-Krajewski, J. L., Chebbo, G. \& Saget, A. I998 Distribution of pollutant mass vs volume in stormwater discharges and the first flush phenomenon. Water Res. 32 (8), 2341-2356.

Campisano, A., Creaco, E. \& Modica, C. (in press) Numerical modelling of sediment bed aggradation in open rectangular drainage channels. Urban Water J., DOI:10.1080/1573062X. 2012.739627.

Candela, A., Freni, G., Mannina, G. \& Viviani, G. 2009 Quantification of diffuse and concentrated pollutant loads at the watershed-scale: an Italian case study. Water Sci. Technol. 59 (11), 2125-2135.

Canteras, J. C., Juanes, J. J., Pérez, L. \& Koev, K. 1995 Modelling the coliforms inactivation rates in the cantabrian sea (Gulf of Biscay) from 'in situ' and laboratory determinations of T90. Water Sci. Technol. 32, 37-44.

Crane, S. R. \& Moore, J. A. 1986 Modelling enteric bacterial dieoff: a review. Water Air Soil Pollut. 27, 411-439.

De Marchis, M. \& Napoli, E. 2008 The effect of geometrical parameters on the discharge capacity of meandering compound channels. Adv. Water Resour. 31 (12), 1662-1673.

De Marchis, M. \& Napoli, E. 20I2 Effects of irregular twodimensional and three dimensional surface roughness in turbulent channel flows. Int. J. Heat Fluid Flow 36, 7-17.

De Marchis, M., Napoli, E. \& Armenio, V. 20Io Turbulence structures over irregular rough surfaces. J. Turb. 11 (3), 1-32.

De Marchis, M., Ciraolo, G., Nasello, C. \& Napoli, E. 2012 Windand tide-induced currents in the Stagnone lagoon (Sicily). Environ. Fluid Mech. 12 (1), 81-100.

Deletic, A., Dotto, C. B. S., McCarthy, D. T., Kleidorfer, M., Freni, G., Mannina, G., Uhl, M., Henrichs, M., Fletcher, T. D., Rauch, W., Bertrand-Krajewski, J. L. \& Tait, S. 2012 Assessing uncertainties in urban drainage models. Phys. Chem. Earth 42-44, 3-10.

Donnison, A. M. \& Ross, C. M. Ig99 Animal and human faecal pollution in New Zealand rivers.. NZ. J. Mar. Freshwat. Res. 33 (1), 119-128.

Dotto, C. B. S., Mannina, G., Kleidorfer, M., Vezzaro, L., Henrichs, M., McCarthy, D. T., Freni, G., Rauch, W. \& Deletic, A. 2012 Comparison of different uncertainty techniques in urban stormwater quantity and quality modelling. Water Res. 46 (8), 2545-2558.

EC (European Community) 2006 Directive 2006/7/EC of the European Parliament and of the Council concerning the management of bathing water quality and repealing Directive 76/160/EEC. OJ L64, 4 March, 37-51.

Evison, L. M. I988 Comparative studies on the survival of indicator organisms and pathogens in fresh and sea water. Water Sci. Technol. 20 (11/12), 309-315.

Freni, G., Mannina, G. \& Viviani, G. 2oroa Urban water quality modelling: a parsimonious holistic approach for a complex real case study. Water Sci. Technol. 61 (2), 521-536.
Freni, G., Mannina, G. \& Viviani, G. 2orob Emission standards versus immission standards for assessing the impact of urban drainage on ephemeral receiving water bodies. Water Sci. Technol. 61 (6), 1617-1629.

Fu, G., Khu, S.-T. \& Butler, D. 20Io Optimal distribution and control of storage tank to mitigate the impact of new developments on receiving water quality. J. Environ. Eng. 136 (3), 335-342.

Garcia-Barcina, J. M., Oteiza, M. \& Sota, A. D. L. 2002 Modelling the faecal coliform concentrations in the Bilbao estuary. Hydrobiologia 475-476, 213-219.

Glasoe, S. \& Christy, A. 2004 Coastal Urbanization and Microbial Contamination of Shellfish Growing Areas. PSAT04-09, State of Washington, Olympia Washington. http://www.psat. wa.gov/Programs/shellfish/sf_lit_review0604.pdf.

Harremoës, P. 2002 Integrated urban drainage, status and perspectives. Water Sci. Technol. 45 (3), 1-10.

Harris, E. L., Falconer, R. A. \& Lin, B. 2004 Modelling hydroenvironmental and health risk assessment parameters along the south Wales coast. J. Environ. Manage. 73, 61-70.

Huber, W. C. \& Dickinson, R. E. I988 Storm Water Management Model-SWMM, Version 4 User's Manual. US Environmental Protection Agency, Athens Georgia, USA.

Jewell, T. K. \& Adrian, D. D. 1978 SWMM storm water pollutant washoff function. J. Environ. Eng. Div. 104 (5), 1036-1040.

Kashefipour, S. M., Lin, B. \& Falconer, R. A. 2006 Modelling the fate of faecal indicators in a coastal basin. Water Res. 40, art. $1413-1425$.

Launder, B. E. \& Spalding, D. B. 1974 The numerical computation of turbulent flows. Comput. Meth. Appl. Mech. Eng. 3 (2), 269-289.

Martins, F. A., Janeiro, J., Gabriel, S., Venâncio, A. \& Neves, R. 2009 Integrated monitoring of South Portugal water bodies: a methodology towards WFD. Water Sci. Technol. 60 (8), 1979-1988.

McCarthy, D. T., Deletic, A., Mitchell, V. G., Fletcher, T. D. \& Diaper, C. 2008 Uncertainties in stormwater E. coli levels. Water Res. 42 (6-7), 1812-1824.

Meays, C. L., Broersma, K., Nordin, R. \& Mazumder, A. 2004 Source tracking faecal bacteria in water: a critical review of current methods. J. Environ. Manage. 73, 71-79.

Napoli, E., Armenio, V. \& De Marchis, M. 2008 The effect of the slope of irregularly distributed roughness elements on turbulent wall-bounded flows. J. Fluid. Mech. 613, 385-394.

Nash, J. E. \& Sutcliffe, J. V. 1970 River flow forecasting through the conceptual model. Part 1: a discussion of principles. J. Hydrol. 10 (3), 282-290.

Noble, R. T. \& Fuhrman, J. A. 20oI Enteroviruses detected by reverse transcriptase polymerase chain reaction from the coastal waters of Santa Monica Bay, California: low correlation to bacterial indicators. Hydrobiologia 460 (1-3), 175-184.

Olawoyin, R., Nieto, A., Grayson, R. L., Hardisty, F. \& Oyewole, S. 2013 Application of artificial neural network (ANN)-selforganizing map (SOM) for the categorization of water, soil and sediment quality in petrochemical regions. Expert Syst. Appl. 40 (9), 3634-3648. 
Roman, F., Stipcich, G., Armenio, V., Inghilesi, R. \& Corsini, S. 2010 Large eddy simulation of mixing in coastal areas. Int. J. Heat Fluid Flow 31 (3), 327-341.

Schulz, M., Buttner, O., Baborowski, M., Bohme, M., Matthies, M. \& von Tumpling, W. 2009 A dynamic model to simulate arsenic, lead, and mercury contamination in the terrestrial environment during extreme floods of rivers. Clean 37 (3), 209-217.

Scroccaro, I., Ostoich, M., Umgiesser, G., De Pascalis, F., Colugnati, L., Mattassi, G., Vazzoler, M. \& Cuomo, M. 2010 Submarine wastewater discharges: dispersion modelling in the Northern Adriatic Sea. Environ. Sci. Pollut. Res. 17 (4), 844-855.

Umgiesser, G., Mattassi, G., Scroccaro, I., Ostoich, M. \& Vazzoler, M. 2008 The use of numerical modeling in Italian watershed management. In: Sustainable Use and Development of Watersheds (I. E. Gönenç, J. P. Wolflin \& R C. Russo, eds). Springer Science, Dordrecht, The Netherlands, pp. 243-261.

Vijay, R., Sardar, V. K., Dhage, S. S., Kelkar, P. S. \& Gupta, A. 2010 Hydrodynamic assessment of sewage impact on water quality of Malad Creek, Mumbai, India. Environ. Monit. Assess. 165, 559-571.

Wu, J. I982 Wind-stress coefficients over sea surface from breeze to hurricane. J. Geophys. Res. 87, 9704-9706.

Zhao, L., Li, Y., Zou, R., He, B., Zhu, X., Liu, Y., Wang, J. \& Zhu, Y. 2013 A three-dimensional water quality modeling approach for exploring the eutrophication responses to load reduction scenarios in Lake Yilong (China). Environ. Pollut. 177, 13-21.

First received 5 March 2013; accepted in revised form 23 April 2013 